\title{
KEPEMIMPINAN HINDU DALAM CERITA TANTRI NANDHAKA HARANA
}

\author{
Ida Bagus Subrahmaniam Saitya ${ }^{1}$ I Made Pasek Subawa ${ }^{2}$ \\ Institut Hindu Dharma Negeri (IHDN) Denpasar \\ subrahmaniam@ihdn.ac.id
}

\begin{tabular}{|c|c|}
\hline \multicolumn{2}{|c|}{$\begin{array}{l}\text { Riwayat Jurnal } \\
\text { Artikel diterima: } 18 \text { Desember } 2019 \\
\text { Artikel direvisi: } 21 \text { Februari } 2020 \\
\text { Artikel disetujui: } 16 \text { April } 2020\end{array}$} \\
\hline $\begin{array}{l}\text { Kata Kunci: } \\
\text { kepemimpinan Hindu, } \\
\text { cerita Tantri Nandhaka } \\
\text { Harana }\end{array}$ & $\begin{array}{l}\text { Abstrak } \\
\text { Nandhaka Harana adalah nama sebuah buku cerita yang di } \\
\text { dalamnya terdapat cerita-cerita mengenai kehidupan binatang dan } \\
\text { manusia dalam bentuk pupuh dan kidung. Cerita Tantri Nandhaka } \\
\text { Harana adalah mengandung kiasan-kiasan yang indah dan } \\
\text { bermanfaat bagi hidup dan kehidupan. Cerita Tantri Nandhaka } \\
\text { Harana mengandung ajaran kepemimpinan agama Hindu yang } \\
\text { dapat memberikan gambaran kepada pemimpin Hindu untuk } \\
\text { menjadi pemimpin yang berkarakter. Seorang pemimpin di dalam } \\
\text { cerita Tantri Nandhaka Harana harus berpedoman atas dharma, } \\
\text { karena dengan dharma maka seorang pemimpin dapat mencapai } \\
\text { moksa. Pemimpin hendaknya memiliki etika yang baik, } \\
\text { menerapkan prinsip tri kaya parisudha, yaitu berpikir yang baik } \\
\text { (manacika parisudha), berkata yang baik (wacika parisudha), dan } \\
\text { berbuat yang baik (kayika parisudha). }\end{array}$ \\
\hline $\begin{array}{l}\text { Keyword: } \\
\text { Hindu leadership, } \\
\text { Tantri Nandhaka } \\
\text { Harana story }\end{array}$ & $\begin{array}{l}\text { Abstract } \\
\text { Tantri Nandhaka Harana is the name of a story book in which } \\
\text { there are stories about animal and human life in the form of } \\
\text { pupuh and kidung. Tantri Nandhaka Harana story is containing } \\
\text { beautiful and beneficial figures of speech for life and life. The } \\
\text { Tantri Nandhaka Harana story contains teachings of the } \\
\text { leadership of the Hindu religion which can give a picture to } \\
\text { Hindu leaders to become leaders with character. A leader in the } \\
\text { Tantri Nandhaka Harana story must be guided by dharma, } \\
\text { because with dharma a leader can reach moksa. Leaders should } \\
\text { have good ethics, apply the tri kaya parisudha, which is good } \\
\text { thinking (manacika parisudha), say good (wacika parisudha), } \\
\text { and do good (kayika parisudha). }\end{array}$ \\
\hline
\end{tabular}




\section{Pendahuluan}

Kepemimpinan adalah konsekuensi logis dari timbulnya suatu kehidupan di masyarakat. Pemimpin seyogyanya adalah pribadi yang dikorbankan, maksudnya segala bentuk kepentingan pribadi harus direlakan untuk kepentingan bersama agar tercapainya sebuah cita-cita yang telah disepakati sebelumnya.

Pada hakekatnya setiap kelompok masyarakat pasti membutuhkan sosok yang menjadi panutan, baik itu sebagai pengambil keputusan, pelindung ataupun pengayomnya, maka disini dibutuhkan seseorang yang mempunyai nilai lebih untuk dijadikan seorang pemimpin pada kelompok tersebut. Kepemimpinan menggambarkan hubungan antara pemimpin dengan yang dipimpin dan bagaimana seorang pemimpin mengarahkan yang dipimpin. Pemimpin dapat mempengaruhi perilaku para bawahan melalui pendekatan dalam mengelola manusia.

Kepemimpinan sebagai proses pengaruh-mempengaruhi antara pribadi atau antara orang dalam suatu situasi tertentu, melalui proses komunikasi yang terarah untuk mencapai tujuan tertentu (Ya'qub, 1984:124). Kepemimpinan diartikan sebagai pelaksanaan otoritas dan pembuatan keputusan. Ada juga yang mengartikan suatu inisiatif untuk bertindak yang menghasilkan suatu pola yang konsisten dalam rangka mencari jalan pemecahan dari suatu persoalan bersama (Toha, 2007:259).

Di dalam ajaran Hindu, ajaran atau ilmu kepemimpinan disebut nīti śāstra. Nìti śāstra mengandung ajaran kepemimpinan yang bersifat umum dan praktis berlandaskan ajaran agama Hindu, nìti śāstra tidak hanya ilmu pengetahuan bagi para negarawan atau politisi saja, melainkan juga bagi semua orang.

Seorang pemimpin dalam kepemimpinan Hindu merupakan tokoh yang menerangi dan mencintai sesame manusia, tidak membenci siapapun, dermawan, hidup ditengah-tengah dan melayani rakyatnya. Pemimpin itu dilantik untuk kejayaan Negara, untuk melindungi warga dan rakyatnya serta untuk menjaga kehormatan dan keselamatan bangsa. Sifat-sifat seorang pemimpin adalah pemberani, mamperbaiki dan melindungi kemakmuran masyarakat (Titib, 1996:471).

Di dalam ajaran agama Hindu, ajaran kepemimpinan yang cukup dikenal di masyarakat adalah ajaran astra brata. Ajaran asta brata merupakan nasihat dari Rama kepada Wibhīsaṇa setelah perang, ajaran tersebut termuat di dalam Mānava Dharmaśāstra dan Kakawin Rāmāyana. Dijelaskan bahwa seorang pemimpin diharapkan memiliki sifat-sifat kepemimpinan delapan dewa, yaitu Indra, Vayu, Yama, Surya, Agni, Varuna, Candra, dan Kuvera. Dewa Surya (matahari), seorang pemimpin diharapkan memberikan penerangan secara adil dan merata kepada seluruh rakyat yang dipimpinnya serta selalu berbuat berhati-hati. Dewa Candra (bulan), seorang pemimpin diharapkan memiliki sifat kelembutan dan menciptakan ketenangan, dan ketentraman di lingkungannya. Dewa Vayu (angin), seorang pemimpin seorang pemimpin hendaknya selalu dapat mengetahui dan menyelidiki keadaan serta kehendak yang sebenarnya terutama keadaan masyarakat yang hidupnya paling menderita.

Dewa Kuvera (kekayaan) yang artinya seorang pemimpin hendaknya harus bijaksana dalam menggunakan dana atau uang serta selalu ada hasrat untuk mensejahterakan masyarakat dan tidak menjadi pemboros yang akhirnya dapat 
merugikan negara dan masyarakat. Dewa Varuna (lautan) yang artinya seorang pemimpin hendaknya dapat memberantas segala jenis penyakit yang berkembang di masyarakat, seperti pengangguran, pencurian, dan pengacau keamanan negara. Dewa Agni (api), seorang pemimpin hendaknya harus memiliki sifat-sifat selalu dapat memotivasi tumbuhnya sifat ksatriya dan semangat yang berkobar dalam menundukkan musuh-musuhnya. Dewa Yama berarti seorang pemimpin mengikuti sifat-sifat Dewa Yama, yaitu menciptakan hukum, menegakkan hukum dan memberikan hukuman secara adil kepada setiap orang yang bersalah. Dewa Indra (hujan), seorang pemimpin hendaknya mengikuti sifat-sifat Dewa Indra sebagai dewa pemberi hujan atau dikenal dengan memberi kesejahteraan kepada rakyat.

Ajaran kepemimpinan Hindu tidak hanya asta brata, di dalam teks-teks sastra agama, baik berbahasa Sanskerta maupun Jawa Kuna terdapat ajaran kepemimpinan. Terjemahan lontar-lontar berbahasa Jawa Kuna penting karena untuk menjembatani pembaca yang kurang mampu memahami bahasa Sanskerta dan bahasa Jawa Kuna. Aktualisasi hormatnya umat Hindu di Bali dapat dilihat pada tradisi nyastra. Istilah anak nyastra "orang berilmu" dalam masyarakat Bali, walaupun dalam kenyataannya seorang belum tentu seluas itu penguasaan pengetahuannya. Namun, karena ia senang membaca dan menulis dan dapat berbuat kebaikan/kebajikan terhadap sesama, biasanya orang itu mendapat tempat terhormat di kalangan masyarakat Bali (Bagus, 1980:8). Dengan adanya hari raya Saraswati dan tradisi nyastra di Bali, maka akan terlihat kesungguhan orang Bali menghormati karya sastranya yang suci dan sakral. Tradisi nyastra terlihat dalam proses mabebasan dan penyalinan lontar.

Penganut agama Hindu di Bali masih mempercayai akan keberadaan dan kebenaran mitos, sehingga lontar-lontar yang memuat mitologi tetap mendapat perhatian bahkan sangat dikeramatkan. Melalui mitos, masyarakat digiring untuk mulai berpikir tentang inti kesemetaan, dengan media kisah-kisah para dewa yang bisa dinikmati dari berbagai kelas pemikiran. Lontar-lontar di Bali memiliki bentuk dan isi yang beraneka ragam. Hal ini terlihat dalam pengelompokan lontar-lontar di Gedong Kirtya, Singaraja. Pengelompokan tersebut menurut Cika (2006:2) digolongkan menjadi 6 (enam) jenis, yaitu :

a. Weda, meliputi Weda, Mantra, Kalpasastra.

b. Agama, meliputi Palakerta, Sasana, Niti.

c. Wariga, meliputi Wariga, Tutur, Kanda, Usada.

d. Itihasa, meliputi Parwa, Kakawin, Kidung, Geguritan.

e. Babad, meliputi Pamancangah, Usana, Uwug.

f. Tantri, meliputi Tantri, Satua.

Dari pengelompokan di atas, salah satunya adalah mengenai kelompok Tantri. Ada 3 jenis cerita Tantri, yaitu Tantri Kamandaka, Tantri Nandhaka Harana, dan Tantri Pisācārana, dalam makalah ini yang digunakan adalah cerita Tantri Nandhaka Harana. Ketertarikan didasarkan pada alasan bahwa pertamatama Cerita Tantri Nandhaka Harana merupakan karya sastra Bali sebagai produk budaya Bali yang sangat perlu dilestarikan keberadaannya. Kedua, dibalik cerita Tantri Nandhaka Harana terselubung ajaran kepemimpinan agama Hindu yang dapat memberikan gambaran kepada pemimpin Hindu untuk menjadi pemimpin yang berkarakter. Ketiga, mengembalikan jati diri masyarakat Bali melalui 
pemahaman terhadap betapa pentingnya cerita pada umumnya, khususnya Cerita Tantri Nandhaka Harana, dalam kehidupan masyarakat Bali yang telah hanyut dalam arus globalisasi.

\section{Pembahasan \\ Cerita Tantri Nandhaka Harana}

Tantri Nandhaka Harana adalah nama sebuah buku cerita yang di dalamnya terdapat cerita-cerita mengenai kehidupan binatang dan manusia dalam bentuk pupuh dan kidung. Cerita Tantri Nandhaka Harana adalah mengandung kiasankiasan yang indah dan bermanfaat bagi hidup dan kehidupan. Tantri Nandhaka Harana diawali dengan cerita Sri Maharaja Aiswarya Dala yang setiap malam supaya didampingi oleh istri baru dan patihnya Bandeswarya dititahkan untuk mengurus hal itu. Lama-kelamaan, ketika Patih Bandeswarya tak dapat lagi melaksanakan tugas itu karena semua gadis di wilayah itu sudah habis, maka Tantri sebagi anak Patih Bandeswarya dengan ikhlas menawarkan diri untuk melayani sang Raja, dan ternyata Tantri mampu meluluhkan hati Sang Raja melalui kemahirannya dalam bercerita, yang dilakukannya selama tiga puluh hari (Zoutmulder, 1994: 545).

Kata Tantri, disamping dapat berarti garis (silsilah), judul karya sastra, gadis dengan sifat khas sebagai tokoh utama dalam karya sastra. Tantri, juga dapat berarti tali senar kecapi (Zoetmulder, 2011:25). Tali senar kecapi adalah resonasi. Tantri adalah teks tulisan atau lisan sebuah resonasi. Tantri sebagai tali senar kecapi, jika dipetik dengan lembut maka akan melantunkan nada-nada indah yang dapat menghibur hati yang sedang kebingungan (moha). Tantri merupakan wacana yang hadir dalam sejumlah teks yang berhasil dibaca dalam sejumlah naskah seperti pewayangan di Bali.

Cerita Tantri dalam tulisan ini adalah, Ni Diah Tantri seorang anak dari Patih Bandeswarya yang memiliki kemahiran bercerita berbingkai tentang binatang sehingga terdapat banyak nilai-nilai kepemimpinan, yang membuat sang raja sangat mengagumi dan heran serta bangga akan kepandaian Ni Diah Tantri bercerita yang diambil dari bait sloka yang indah. Melayang-layang perasaan Sang Raja, rasanya tidak melintas dijagat raya, tiada lagi istri lain yang melintas dibenak beliau, hanya Ni Diah Tantri.

\section{Dharma Pemimpin dalam Cerita Tantri Nandhaka Harana}

Kepemimpinan adalah suatu seni, kesanggupan, ataupun tekhnik untuk membuat kelompok atau orang-orang mengikuti dan menaati segala apa yang dikehendaki dan membuat mereka antusias mengikutinya. (Yudana, 2015:1). Menurut Rai dan Suarningsih (2019:2) pemimpin adalah seorang pribadi yang memiliki kecakapan dan kelebihan di satu bidang, mampu mempengaruhi orang lain untuk bersama-sama melakukan aktivitas dalam mencapai tujuan tertentu. Ada beberapa fungsi pokok kepemimpinan, yaitu:

1. Fungsi intruksi, pemimpin sebagai komunikator dalam menentukan keputusan yang dilaksanakan secara efektif.

2. Fungsi konsultasi, pemimpin yang memperhatikan sisi keberadaan orang lain, berkomunikasi, berkoordinasi pemimpin dengan yang dipimpinnya. 
3. Fungsi partisipasi, pemimpin yang mampu menumbuhkan peran serta masyarakatnya dalam melaksanakan keputusannya.

4. Fungsi delegasi, pemimpin mampu melimpahkan kewenangan baik melalui persetujuan ataupun tidak.

5. Fungsi pengendalian, dapat diwujudkan melalui kegiatan bimbingan, pengarahan, koordinasi, dan pengawasan.

Berkaitan dengan gaya kepemimpinan, ada beberapa gaya kepemimpinan, sebagai berikut:

1. Gaya otokrasi, dicirikan dengan gaya kepemimpinan yang terpusat bersumber dari pimpinan, komunikasi yang satu arah, pengawasan yang ketat, tidak adanya saran, dan lebih banyak terdapat kritik dibandingkan saran.

2. Gaya birokratis, bercirikan adanya aturan yang kaku dalam suatu keputusan, dan kurang fleksibilitas antara pimpinan dan bawahannya.

3. Gaya kepemimpinan demokratis, yang bercirikan dengan adanya wewenang pemimpin yang tidak mutlak, adanya pelimpahan kewenangan, komunikasi yang bersifat timbal balik, pengawasan dilakukan secara wajar, terdapat konsep saling percaya dan menghormati antara pimpinan dengan yang dipimpinnya.

4. Gaya kepemimpinan Laize Faire, yang bercirikan dengan diberikannya bawahan keleluasaan/fleksibel dalam bertugas dengan sesuai aturan yang telah ditetapkan (Rai dan Suarningsih, 2019:2-3)

Gaya kepemimpinan sesuai di atas sangat bergantung kepada karakter seorang pemimpin. Dengan fungsi pokok kepemimpinan seperti di atas, maka seorang pemimpin memiliki kewajiban yang sangat mulia, yang harus mampu mengemban tugas yang diberikan dan juga mampu mensejahterakan masyarakat yang dipimpinnya. Di dalam ajaran Hindu kewajiban berarti dharma.

Dharma bukan hanya berarti kewajiban, tetapi juga berarti kebaikan, disamping itu juga berarti kebenaran. Menjadi seorang pemimpin harus berpegang teguh atas dharma. Berdasarkan pandangan tersebut, maka kebenaran yang akan dikejar terus adalah nilai-niai kebenaran agama Hindu yang terdapat dalam pupuh Cerita Tantri Nandhaka Harana, sebagai berikut.

\section{Pupuh Demung Sawit}

Ih dūran ngong yan gaçcat ing para nätha tuwi prtakjana tan bhèdang subhūkti matsyaganganpan̄̄ mastawa mwang tang drāksa kiñca teka ning wastra Ian kampuh sama tunggal so-wangdyastunyan ring smarā kāryya sasuka ping indriya nda tan lén yan pangidep-ingsun.

Terjemahannya :

Ah, sebenarnya tidak jauh berbeda saya dengan para ratu lainnya termasuk dengan semua rakyat, buktinya apa yang mereka makan baik nasi, sayur- 
sayuran, ikan dan lain sebagainya; demikian juga dalam hal berbusana toh memakai selembar kain maupun kampuh. Begitu juga dalam asmara tidak berbeda dengan mereka.

Dari pernyataan Sang Raja di atas, telah mencerminkan bahwa beliau (Raja) sangat mengerti dan memahami tentang nilai-nilai kebenaran/Dharma, dimana beliau sangat menghargai ratu lainnya, rakyat baik dalam hal makan maupun berpakaian, serta bersenang-senang dengan seorang wanita, ini menandakan tidak ada jarak antara raja dengan rakyatnya dan semua itu adalah sejajar. Pernyataan raja di atas didukung dan diperkuat dengan pernyataan beliau seperti pupuh di bawah ini.

Apan tan rwa liněwih dè nira sang yajamana yang ring rājya mān, dhala tan lèn sang mahā bhüpati kantinèn yan ring wanā cala sang yogīçwara winuwus guhya çastra Ongkara kanti diwyapaka ning tuduh.

Terjemahannya :

Karena sebenarnya hanya satu hal yang dipentingkan oleh orang bijaksana yakni, apabila di dunia rajalah menjadi sahabatnya, bila di hutan para pertapa (yogi swara) dan bila dalam aksara suci Omkkara sebagai sahabat utama dan bertuah

Pupuh di atas lebih mempertegas dan menyiratkan nilai-nilai kebenaran bahwa, untuk menjadi pemimpin yangn bijaksana hendaknya mampu dan harus dapat menyesuaikan diri dengan lingkungan dimana berada, sebagaimana hendaknya berperilaku jika berada di dunia ini Raja-lah menjadi sahabat, dalam hal ini bahwa diharapkan mampu menyesuaikan diri dengan pemerintahan yang ada. Demikian juga jika kita berada di hutan maka sahabat yang terbaik untuk kita ajak berteman adalah para yogi, dimana dalam kehidupan di hutan hanya para yogilah yang dapat memberikan tuntunan hidup untuk menuju kebenaran yang abadi. Demikian juga dalam hal belajar dari sastra agama Hindu, maka hendaknya kita belajar dari aksara suci $O \dot{m}$, aksara $O \dot{m}$ sebagai simbol aksara suci yang dapat memberikan ajaran kebenaran yang abadi, yang harus dilakukan untuk mendapatkan ilmu pengetahuan sejati karena sangat berguna untuk mencapai tujuan hidup sebagai umat beragama yaitu, untuk mencapai kedamaian sekala maupun niskala. Seorang pemimpin juga harus berbakti kepada Tuhan dengan berlandaskan dharma. Di dalam catur purusa artha, ada empat tujuan hidup dari manusia, yaitu dharma, artha, kama, dan moksa. Pemimpin Hindu harus mampu mengimplementasi tujuan hidup tersebut untuk dapat mencapai moksa yang merupakan tujuan akhir dari umat Hindu. Pemujaan kepada Sanghyang Śiwa, untuk mencapai tujuan akhir hidup sebagai umat beragama yaitu untuk mencapai moksa seperti yang dijelaskan berikut ini.

Hentyārsān-ira Çri Singhā dhipati wus-apriya sama lutut tan wyar kahering sojar Çri Surabhija jāti nityā mangun tapa brata çidhanta kang pinuh 
putěr ing tutur pinahayu saņdhining pamatěluning jñana nis prha çūnya nirbbhana tan pawastun.

tuhu kapo ling ping brāhmāndha puraņa ring sang sāmpunanmu wak çuddha jāti krtta samayéng don wyākti ndātan paupama ring sukaning twas anmu katwang-ikang bhühwiryya amukti mās maṇi wadhu apan tan swartha katon çakti ning-indriyā-naput.

Terjemahannya :

Betapa senang hatinya Prabhu Singa setelah bersahabat kental dengan Sang Nandhaka serta melaksanakan segala tuntunannya selalu melaksanakan tapa brata yang disebut Sri Danta (memutih), tekun melaksanakan meditasi peninggalan Tri Nadi sehingga menjadi suci serta mencapai moksa (Nirwana).

Memang benar apa yang tercantum dalam Brahmanda Purana bahwasanya orang yang telah mendapat wahyu sejati, memahami hakekat tujuan hidup sungguh tak ada taranya kebahagiaan itu sedangkan orang yang dihormati dan dikagumi di dunia serta menikmati kepuasan dunia berupa istri, anak dan emas, intan berlian, yang demikian tidak kekal adanya sepanjang diliputi oleh hawa nafsu.

Uraian pupuh di atas menyiratkan bahwa untuk mencapai moksa sebagai tujuan akhir hidup ini dapat juga dilakukan dengan cara tapa brata yang disebut Sri Danta (memutih), tekun melaksanakan meditasi peninggalan Tri Nadi sehingga menjadi suci serta mencapai moksa. Cara yang lain juga dapat dilakukan seperti jalan mendengarkan wejangan dari para pertapa yaitu orang suci (pendeta) tentang tattwa diatmika, ajaran kesucian dan kebenaran. Jadi keberhasilan kepemimpinan Hindu juga dapat berlangsung melalui mendengarkan dengan baik sehingga menghasilkan hal-hal yang baik. Sebagaimamana tersirat pada pupuh dibawah ini.

Antyānta suka Çri nrpati Druma sinwagatan déni sang para tapa tumulyā ngucap marmmāning-/-çokā nis amurang laku wétning kasor ing jurit muwang pürwwakanya winuni sang tapā ngrs nala nirā ngrungū.

pan sama santa buddhi çuci ulahing sang tapa asih éng kawlasārsa nitya madhangi twas wngi Çrì narapati lagyā takwan pūrwwaning manuk pékat tinmu niré nguni mangké ki punang-atat sumahur.

Terjemahannya :

Amat bahagia hati baginda raja Sri Gaja Druma disambut dan diladeni oleh para pertapa. Saat itulah beliau menyampaikan kesedihan beliau pergi kehutan disebabkan karena kalah dalam peperangan. Dari awal beliau memaparkan permasalahannya, sehingga para pertapa kasihan mendengarkannya. 
Karena berpegang pada budi sadu dan melaksanakan prihal kesucian para pertapa merasa kasihan terhadap orang yang dilanda penderitaan serta berupaya memberi tuntunan sinar suci pada orang yang sedang kebingungan. Sang Prabhu lalu mohon penjelasan mulai dari menemui burung Beo yang tadinya ngomong sebagai berikut.

Sarjjawā-rūm singgih sang Çrì Gaja Druma lah to rěngön pukulan kang pékat uni katmu de sang katong wyakti bhedha ring patik bhra kinudhang de ra dhang guru baryya na ngrungu ujar-ing-aji dyatmikéngtutur krtta dharmma ginugon tang pékat pinanggih dangu.

Terjemahannya :

Daulat Sri Baginda berkenanlah mendengar penjelasan hamba. Adapun burung Beo yang paduka temui terdahulu memang berbeda dengan hamba ini yang merupakan piaraan beliau Pendeta Guru yang kesehariannya mendengarkan tattwa diatmika, ajaran kesucian dan kebenaran.

Pada uraian di atas dinyatakan oleh seekor burung Beo kepada Sri Baginda, yaitu "daulat Sri Baginda berkenanlah mendengarkan penjelasan hamba" penjelasan yang dimaksud adalah penjelasan tentang tattwa diatmika, ajaran kesucian dan kebenaran yang ia peroleh dalam keseharian dari Pendeta Guru. tattwa diatmika, ajaran kesucian dan kebenaran, merupakan cermin seorang pemimpin yang perpegang atas dharma, sebagai pedoman umat dalam mengimplementasikan ajaran agama Hindu Khususnya tentang Tattwa. Ajaran Tattwa juga dapat disimak pada Rgveda X.50.29 (Titib (1997:321), orang yang dermawan memproleh kata pujian, yaitu So cin-nu sakhyā narya inah stutah yang artinya, Tuhan Yang Maha Esa dipuja karena kebajikan-nya dan tingkah laku yang ramah.

Ini berarti bahwa umat manusia melakukan pemujaan kepada Ida Sang Hyang Widhi Wasa (Tuhan Yang Maha Esa) karena beliau juga melakukan kebajikan dan tingkah laku yang ramah. Dengan demikian setiap yang dapat melakukan kebajikan dengan perilaku yang ramah akan mendapat perhatian juga dari beliau, seperti yang terungkap pada, Rgveda. VII.32.8 (Titib, 1997:321) yaitu; Prnan it prnate mayah, artinya, "Tuhan Yang Maha Esa yang pemurah memberkahi orang yang penuh kebajikan". Uraian ini menandakan bahwa siapapun di muka bumi ini yang berbuat kebajikan akan diberkahi-Nya. Kebajikan yang dimaksudkan dalam hal ini adalah kebenaran (dharma), kebenaran yang abadi di dunia ini adalah Tuhan, Barang siapa yang berbuat kebenaran ini berarti dialah yang dapat mendekatkat diri dengan Tuhan, bahkan menyatu dengan Tuhan, karena hanya Tuhanlah yang bersifat abadi di Dunia ini. Jadi kebenaran (dharma) merupakan pedoman bagi seorang pemimpin, dengan memahami dan menghayati kebenaran itu umat secara tidak langsung dididik untuk dapat meningkatkan keyakinan akan kebenaran (Tuhan), sehingga dalam hidup ini berusaha untuk selalu berbuat kebenaran. Di dalam Slokāntara 4 dijelaskan. 
Anityam yauwanam rūpamanityo drawyasamcayah, anityah priyasamyogastasmād dharmam sāmacaret.

Terjemahannya:

Keremajaan dan kecantikan rupa itu tidak langgeng. Timbunan kekayaan pun tidak langgeng. Hubungan dengan yang dicintai pun tidak langgeng. Oleh karena itu kita harus selalu mengejar dharma (kebenaran) karena hanya itulah yang langgeng (Sudharta, 2003:18)

Mencermati sloka di atas, maka dapat dianalisis bahwasannya terkandung ajaran dharma (kebenaran), yaitu suatu ajaran yang memberikan pandangan bahwa tidak ada sesuatu yang kekal di dunia ini selain dharma. Dharma yang dimaksud adalah Tuhan itu sendiri yang merupakan identitas dari semua yang ada. Nilai dharma ini mengajarkan supaya umat Hindu memiliki keyakinan yang semakin kuat tentang ajaran agama Hindu yang diwahyukan oleh Tuhan.

\section{a. Etika Pemimpin dalam Cerita Tantri Nandhaka Harana}

Tiga Kerangka Agama Hindu terdiri atas tattwa, susila, dan ācāra. Etika atau susila merupakan salah satu dari Tiga Kerangka Agama Hindu yang akan dianalisis pada teks Cerita Tantri Nandhaka Harana. Etika memiliki tiga arti, yaitu (1) ilmu tentang apa yang baik dan apa yang buruk dan tentang hak dan kewajiban moral (akhlak); (2) kumpulan asas atau nilai yang berkenaan dengan ahlak; (3) nilai mengenai benar dan salah yang dianut suatu golongan atau bermasyarakat (Bertens,1997:5-6). Di sisi lain ditegaskan bahwa etika juga dapat dipakai dalam arti nilai-nilai dan norma-norma moral yang menjadi pegangan bagi seseorang atau suatu kelompok dalam mengatur tingkah lakunya. Etika juga dapat diartikan ilmu tentang yang baik atau buruk.

Etika dalam hal ini adalah, nilai-nilai, norma-norma moral, juga menyangkut benar salah dalam perilaku kehidupan yang tedapat dalam Cerita Tantri Nandhaka Harana bagi seorang pemimpin Hindu. Adapun etika pemimpin dalam cerita Tantri Nandhaka Harana sebagai berikut.

\section{Kawitan}

Tuhu tan kněng-api pratapa sang prabhu kěsyan ni ruktyang sājň̄a ri sawyakti yan Ari Wị̣du nityā-ngdé hulap ing hari Çri Dhara patra sang katong.

Terjemahannya :

Sungguh luar biasa keutamaan yasa dan kerti baginda raja, terpenuhi segala kehendak beliau dan berkuasa bagaikan Dewa Wisnu, selalu membuat takut semua musuh-musuh beliau, Sri Andhara nama baginda raja. 
Manyimak kawitan di atas ternyata tersirat etika pada yasa kerti (perilaku) Sri Andhara sebagai raja, sehingga beliau sangat ditakuti oleh musuh-musuhnya, para musuhnya memandang beliau bagaikan Dewa Wisnu. Dimana Dewa Wisnu adalah seorang Dewa yang memiliki karakter ibaratkan air dalam telaga yang tenang, semua mahluk hidup membutuhkan air untuk hidup, air dapat membuat kesejukan dalah hidup, air dapat membuat mahluk hidup menjadi lebih sejahtra, air pula dapat membuat suasana lebih tenang, lebih nyaman, dan lebih memberikan jaminan untuk dapat hidup lebih lama. Jadi dengan perilaku yang sopan, yang tenang, mengayomi orang lain, serta dapat memberikan sesuatu kepada orang lain (menolong) maka semua ini merupakan nilai-nilai kebaikan (etika). Dari yasa kerti-nya Raja, yang sangat mulia ini menyebabkan semua orang menjadi sangat hormat kepada beliau, lebih-lebih pada para abdi raja seperti para patih, para punggawa, utamanya Kryan Bandeswarya seperti yang tersirat pada kawitan dibawah ini. Dalam ajaran agama Hindu dikenal dengan Tat Twam Asi. Perilaku Raja yang mencerminkan ajaran etika juga tersirat dalam pupuh dibawah ini.

Bĕk dè ning nawa ratnā-di nrpati wus munggwing maii māya Singhasana mās tatur asan,dhing Ian sang parāsi ring kamala sana kasongan açoka mayung lagyā sěhĕn skar rurū kinusèngali ndan Çri Narapati smu smitā-rūm singgih bapa dhāng guru.

Terjemahannya :

Dengan penuh perhiasan emas, intan, berlian "Nawa Ratna (sembilan warna) baginda raja duduk dikursi? Singgasana yang terbungkus oleh emas permata, didampingi para purohita yan berada dipendopo dibawah pohon Angsoka yang rindang sedang berbunga. Berserakan (yang sedang) digoyangkan oleh si Kumbang. Sambil tersenyum baginda raja berkata: ampun pendeta guru.

Pada pupuh di atas tersirat perilaku Raja, yaitu ketika Raja duduk dalam persidangan dengan busana agung, yaitu perhiasan emas, intan, berlian, Nawa Ratna (sembilan warna) dan duduk di singgasana yang terbungkus dengan emas permata yang bergitu megah, masih juga beliau menunjukan rasa hormatnya kepada para purohito-nya (pendetanya) dengan ucapan ampun pendeta guru dan sedikitpun tidak tercermin perilaku Raja yang sombong, angkuh, sekalipun berkuasa menjadi seorang Raja yang besar, agung dan berkuasa. Perilaku Raja seperti ini dilakukan di samping untuk menghormati seorang guru/pendeta, juga seorang Raja/penguasa untuk tetap menjaga persahabatan dengan guru/purohito demikian juga sebaliknya, sebagaimana tercermin pada pupuh di bawah ini.

kadyāngganing ütpti stiti dāryya tèng praliņa katrinya tan wĕnang wiyoga nasta sang bhüpati yan tan sang yatiçwara kinanti nirwang kapān,dhitan tan wring kuttara simpěning gati arddha paksa apunggung.

Terjemahannya :

Seumpama bagaikan Utpeti, Sthiti, pasti Pralina bagian akhirnya. Ketiga aspek tersebut tidak dapat dipisahkan satu dengan yang lainnya. Sebagai raja 
akan hancur apabila tidak bersahabat dengan pendeta/purohita, tidak bermanfaat kepanditaan itu bila tidak mengetahui/memahami ajaran Kutara Manawa, ikut bersuka duka dengan orang bodoh.

Menyimak uraian di atas, Raja mempunyai perumpamaan bahwa semua yang ada di dunia ini tidak terlepas dari Utpeti, Sthiti, dan Pralina, yaitu; lahir, hidup, dan mati. Semua yang ada didunia ini satupun tidak terlepas dari hukum alam yaitu, lahir, hidup, dan pada akhirnya adalah mengalami kematian atau kehancuran. Sebagai Raja akan mengalami keruntuhan dari kekuasaan apabila tidak bersahabat dengan pendeta/purohita, demikian juga sebaliknya, jika pendeta/purohita tidak mengetahui/memahami ajaran Kutara Manawa yaitu ikut bersuka duka dengan orang yang tidak tahu apa-apa (bodoh), maka seorang pendeta akan tidak ada manfaatnya di dunia ini. Etika ini memberikan cermin kepada setiap mahluk hidup yang ada di muka bumi ini lebih-lebih kepada manusia utamanya kepada Raja (penguasa), Pendeta, serta masyarakat luas untuk lebih memahami dan mampu mengimplementasikan bahwa di dalam mengarungi kehidupan di dunia ini hendaknya mampu melakukan hubungan yang baik kepada setiap yang ada di dunia ini yaitu saling menghoramati, saling memahami, sehingga terwujudlah suatu kedamaian hati yang abadi (Santih). Dalam hal ini hendaknya kita mampu mengimplementasikan ajaran agama Hindu yang disebut Tri Hita Karana. Pada kidung di bawah ini juga mencerminkan perilaku etika/susila.

Nagatang sarama kagman humulat padha mulingéng pungkur ndatandwa prāpta Çri Singhā dipati sawismaya asmu katrsan tan wawang sira tumandhuk marmmarā nantwa héngdoh ih saking èndi sira mrgghāpangaranan to kapuhan twan isun āndhulu.

Terjemahannya :

Melihat kejadian ini anjing-anjing itu mundur ketakutan semuanya menoleh ke belakang. Tak lama kemudian datanglah Prabhu Singa yang tertegun menyaksikan peristiwa ini, dari jauh beliau bertanya: Maafkan tuan, (kalau boleh saya tahu) tuan dari mana dan siapakah nama tuan, saya sangat kagum.

Kidung di atas mencerminkan perilaku etika/susila adalah ketika Prabhu Singa tertegun melihat pertengkaran si anjing-anjing yang sedang melakukan perburuan, akhirnya Prabhu Singa bertanya, dengan ucapan maafkan tuan (kalau boleh saya tahu) tuan dari mana dan siapa nama tuan?. Ucapan maaf, sebagai awal mohon ijin untuk bertanya oleh Prabhu Singa kepada anjing-anjing ini merupakan etika yang sangat mulia bagi seseorang. Binatang saja dapat melakukan etika itu apalagi manusia, mestinya manusia lebih beretika daripada binatang dalam hidup ini. Ini merupakan cermin yang sangat luar biasa untuk etika/susila (budi pekerti). Perilaku etika juga dapat disimak pada kidung dibawah sebagai berikut.

Huměntasaknéng durggati nuddhā pāpa kléça kalingan-ipun tuhan tumūt manira angiring tan sah-anuhunasuku apti mangké asurudā-yu mār ya ingsa gati ngurangi mangsa wi-/-sayéng dangū. 
Terjemahannya :

Palungguh Pedanda dapat menyucikan kekotoran, penderitaan dan perbuatan dosa hamba. Mulai saat ini ikut berdwijati (mediksa) mengikuti jejak singgih Pedanda, serta mengakhiri Himsa Karma dan mengurangi memakan daging sebagaimana kebebasan dan kesenangan yang lalu.

Pada kutipan di atas sangat mencerminkan perilaku Etika/Susila adalah, perbuatan Pendeta yang dapat menyucikan, Prabhu Singa dari kekotoran, penderitaan dan perbuatan yang penuh dosa. Kesadaran Prabhu Singa ini menyebabkannya untuk ikut meniru langkah Pendeta yaitu meduijati, dengan demikian sejak itu Prabhu Singa berjanji untuk mengurangi makan daging, melakukan perbuatan membunuh sesama (ahimsa karma) dan mulai mengurangi kebebasan dan kesenangan yang telah lalu. Pada kidung di bawah ini juga mencerminkan etika/susila sebagai berikut.

Mangkana Çri Wirakécari kāryyā-tilar bala suka santika karmma kuça trna kang bhi-/-nūkti tan pisan ping rwa sira ping triṇi ingaturan mrgghéwuh tanāhyun sirā māti-māti praņa pāpa tinmu.

Terjemahannya :

Demikianlah perilaku Prabhu Singa kesehariannya, melaksanakan tapa brata (budi sadhu) selalu makan ilalang dan rerumputan meninggalkan rakyatnya (para anjing). Sampai dua tiga kali, beliau diajak berburu untuk mendapat mangsa, beliau tidak mau dengan alasan bahwa perilaku tersebut termasuk himsa karma yang mengakibatkan penderitaan/kesengsaraan.

Uraian kidung di atas sangat mencerminkan perilaku etika/susila pada perilaku yang dilakukan oleh seekor binatang buas yaitu, Prabhu Singa yang dapat melakukan tapa brata (budi sadu), dengan tekun, selalu makan ilalang dan rerumputan, meninggalkan anjing-anjing sebagai pemburu. Prabhu Singa juga tidak mau lagi mengulangi perbuatan untuk menyakiti/berburu, membunuh sesama mahluk hidup, karena perbuatan semacam itu sangat berdosa (ahimsa).

Dari beberapa pupuh di atas, di dalam Sārasamuccaya 156 disebutkan etika dalam menjadi seorang pemimpin seperti yang dijelaskan di bawah ini. matangyan nihan kadāyakênaning wwang tan wāk, kaya, manah, kawarjanā, makolahang aśubhakarma, apan ikang wwang mulahakên ikang hayu, hayu tinêmunya, yapwan hala pinakolahnya, hala tinemunya

Terjemahannya:

Oleh karenanya, ini harus diusahakan orang, jangan dibiarkan kata-kata laksana dan pikiran melakukan perbuatan buruk, karena orang yang melakukan sesuatu yang baik, kebaikanlah diperolehnya; jika kejahatan 
merupakan perbuatannya, celaka yang ditemukan olehnya (Kajeng, dkk 1999:130)

Dari kutipan di atas tersirat bahwa pikiran, perkataan, dan perbuatan seseorang akan memproleh hasil, jika hal yang buruk dipikirkan, diucapkan, dan diperbuat oleh seseorang maka buruk pulalah yang akan diterimanya, demikian sebaliknya jika seorang pemimpin mampu berpikir, berkata, dan berbuat yang baik maka akan menghasilkan yang baik pula. Hal ini dapat memberikan ajaran susila kepada pemimpin Hindu, agar pemimpin Hindu selalu dapat berpikir, berkata-kata, dan berbuat yang baik (susila) agar mendapatkan hasil yang baik untuk menuju kebenaran yang abadi. Demikian juga agar pemimpin Hindu sedapat mungkin dapat menghindari bahkan tidak melakukan untuk berpikir, berkata-kata, serta berbuat yang tidak baik, karena semua ini akan menghasilkan hasil yang buruk dan tidak bermanfaat bagi kehidupan ini.

\section{Penutup}

Seorang pemimpin harus berpegang teguh atas dharma, tidak ada sesuatu yang kekal di dunia ini selain dharma. Dharma yang dimaksud adalah Tuhan itu sendiri yang merupakan identitas dari semua yang ada. Pemimpin Hindu sudah sepatutnya memiliki perilaku yang baik atau memiliki tata susila yang baik. Dengan demikian pemimpin Hindu selalu mampu untuk berpikir, berkata, berbuat yang suci (Trikaya Parisudha) yaitu, berpikir yang suci (manacika), berkata-kata yang suci (Wacika), dan berbuat yang suci (Kayika).

\section{DAFTAR PUSTAKA}

Anonim.(2005). Tantri Kamandaka (Nandhaka Harana) Teks dan Terjemahan dalam Bahasa Indonesia. Surabaya: Paramita.

Bagus, I Gusti Ngurah.(1980). Aksara dalam Kebudayaan, Suatu Kajian Antropologi. Denpasar: Universitas Udayana.

Bertens, K.(1997). Sejarah Filsafat Yunani. Yogyakarta: Kanisius.

Cika, I Wayan.(2006). Kakawin Sabha Parwa Analisis Filologis. Denpasar: Pustaka Larasan.

Kajeng, I Nyoman, dkk.(1999). Sārasamuccaya Dengan Teks Bahasa Sanskerta dan Jawa Kuna. Surabaya: Pāramita.

Rai, Ida Bagus \& Ni Made Suarningsih.(2019). "Konsepsi Asta Brata dalam Kepemimpinan Berlandaskan Tri Hita Karana" Jurnal Kajian Pendidikan Widya Accarya, 10(2), 1-6. Diakses dari http://103.19.229.34/index.php/widyaaccarya/article/view/765.

Sudharta, Tjokorda Rai.(2003). Slokāntara (Untaian Ajaran Etika, Teks, Terjemahan dan Ulasan). Surabaya: Paramita.

Titib, I Made.(1997). Veda Sabda Suci Pedoman Praktis Kehidupan. Surabaya: Paramita.

Toha, Miftah.(2007). Kepemimpinan dalam Manajemen. Jakarta: PT. Raja Grafindo

Ya’qub, Hamzah.(1984). Manajemen Kepemimpinan. Bandung: Diponegoro. 
Yudana, I Made.(2005). Kepemimpinan Wirausaha (Sinkretisme Kepemimpinan Pancasila dan Kepemimpinan Barat). Singaraja: FPIPS-IKIPN.

Zoetmulder, P.J.(1994). Kalangwan Sastra Jawa Kuno Selayang Pandang (Dick Hartoko SJ, Pentj.). Jakarta: Djambatan.

Zoetmulder, P.J. dan S.O. Robson.(2011). Kamus Jawa Kuna Indonesia. Jakarta: PT. Gramedia Pustaka Utama. 